\title{
CONTRIBUIÇÃO DAS AULAS DE CAMPO NO PROCESSO DE ENSINO - APRENDIZAGEM EM DISCIPLINAS DO ENSINO SUPERIOR
}

\author{
THE CONTRIBUTION OF FIELD CLASSES TO THE TEACHING-LEARNING PROCESS \\ IN ACADEMIC DISCIPLINES
}

\author{
Karine do Nascimento ${ }^{1}$ \\ Alexandre Monkolski ${ }^{2}$ \\ Jakeline Galvão de França ${ }^{3}$ \\ Thiago Bergler Bitencourt ${ }^{4}$
}

RESUMO: As aulas de campo constituem atividades que envolvem o deslocamento dos estudantes para ambientes não formais, representados por espaços interativos que fujam da rigorosidade da sala de aula. A proposta do estudo foi avaliar como as aulas de campo interferem no processo de ensino-aprendizagem, funcionando como suporte para a melhoria do aprendizado de conhecimentos teóricos desenvolvidos em sala. Os procedimentos adotados tiveram como base a metodologia de pesquisa-ação, apoiando-se no levantamento bibliográfico com posterior execução de um experimento desenvolvido na disciplina de Apicultura, em turmas regulares do curso de Agronomia. O estudo foi composto de duas etapas: a primeira tratou-se do levantamento de informações concretas que destacassem a importância da utilização das aulas de campo, e a segunda consistiu na elaboração e aplicação de testes para verificar a contribuição dessas aulas quando realizadas na sequência da teoria em sala de aula. Um pré-teste foi aplicado uma semana após a aula de fundamentos teóricos, e depois um pós-teste uma semana após a execução da aula de campo, sobre o mesmo assunto técnico da disciplina. Os resultados obtidos demonstraram uma grande melhora no grau de compreensão sobre o assunto após a aula de campo, sendo que no pós-teste os acadêmicos deram respostas mais detalhadas e com terminologias técnicas e científicas quando

\footnotetext{
${ }^{1}$ Graduação em Licenciatura em Educação do Campo pela Universidade Federal da Fronteira Sul (UFFS), campus de Laranjeiras do Sul-PR. E-mail: karine_neca@hotmail.com

${ }^{2}$ Mestre em Ecologia de Ambientes Aquáticos Continentais pela Universidade Estadual de Maringá (UEM), Graduação em Ciências Biológicas pela Universidade Estadual de Maringá (UEM). Atualmente é professor Adjunto na Universidade Federal da Fronteira Sul (UFFS), campus Laranjeiras do Sul-PR. Tem experiência em docência nas áreas de Zoologia, Ecologia, Gestão e Educação Ambiental. E-mail: alexandre.monkolski@uffs.edu.br.

${ }^{3}$ Mestre e Doutora em Aquicultura pela Universidade Estadual Paulista (UNESP), Graduação em Ciências Biológicas pela Universidade Estadual de Maringá (UEM). Tem experiência na área de Ecologia, com ênfase em Ecologia de Ecossistemas Aquáticos. E-mail: jkgfranca@gmail.com.

${ }^{4}$ Mestre e Doutor em Química Orgânica pela Universidade Federal de Santa Catarina (UFSC), Graduação em Química pela Universidade Federal de Santa Catarina (UFSC). Atualmente é professor Adjunto na Universidade Federal da Fronteira Sul (UFFS), campus Laranjeiras do Sul-PR. Tem experiência na área de Biocatálise, com ênfase em aplicação de lipases. E-mail: bitencourt@uffs.edu.br.
} 
comparadas ao pré-teste, além de subsequente melhoria no desempenho acadêmico expresso numericamente pelo aumento da média das notas.

Palavras-chaves: Ensino-Aprendizagem. Aulas de campo. Ensino superior.

ABSTRACT: Field classes are school activities that involve moving students to non-formal environments, represented by interactive spaces, which are more relaxed than the classroom environment. This study aimed to evaluate how field classes impact the teaching-learning process, supporting the improvement of the learning of theoretical knowledge developed in the classroom. The procedures adopted were based on the action research method, supported by bibliographic survey with subsequent execution of an experiment in the discipline of Apiculture, in regular classes of the Agronomy course. The study was conducted in two stages. In the first stage, concrete information about the importance of field classes was collected. The second stage consisted of the elaboration and application of tests to verify the contribution of these classes when conducted after traditional classes where theoretical foundations were taught. A pre-test was applied one week after the class on theoretical foundations. A post-test was applied one week after the field class on the same technical subject of the discipline. The results obtained showed significant improvement in the level of understanding of the topic after the field class, and in the post-test the students gave more detailed answers and used technical and scientific terminologies compared to the pre-test besides subsequent improvement in academic performance numerically expressed in the increase in the average grades.

Keywords: Teaching-Learning. Field classes. College.

\section{INTRODUÇÃO}

Atualmente, a profissão de professor enfrenta muitos desafios devido ao avanço tecnológico em que as informações se encontram rapidamente disponíveis, o que leva à necessidade de buscar diferentes métodos para despertar o interesse do estudante pelo conteúdo trabalhado. Várias estratégias de ensino-aprendizagem podem ser utilizadas para esse fim, porém, as aulas práticas se destacam como as mais utilizadas, em especial no âmbito universitário, em que os conhecimentos muitas vezes são vistos apenas como objetos para alavancar suas carreiras profissionais ou para cumprimentos de tarefas atreladas ao trabalho de conclusão de um curso, sem a devida preocupação com aspectos de formação para o desenvolvimento das competências profissionais. Usualmente as aulas partem do pressuposto de recepção de informações em quantidade exagerada que não é acompanhada de uma atividade de fixação (VIVEIRO; DINIZ, 2009). Por essa razão, as atividades complementares ao aprendizado obtidas por recepção de informações nas aulas expositivas devem estar associadas à criação de resumos, esquemas, mapas mentais e a experimentação pessoal vivenciada pela participação em aulas práticas (PIAZZI, 2008).

Estratégias de ensino com âmbito prático que desenvolvem habilidade cognitivas e manuais trazem motivação aos acadêmicos, melhorando a apropriação de conhecimentos de uma determinada área. Deste modo, a aula não passará despercebida e se tornará marcante (FERNANDEZ, 2007), uma vez que se obtém um aprendizado significativo que relaciona o conhecimento prévio com o científico. Segundo Viveiro e Diniz (2009), dentre as diversas estratégias adotadas pelos professores, pode-se destacar: aulas expositivas, discussões, 
demonstrações, aulas práticas, aulas laboratoriais, visitas técnicas, e aulas de campo. Sendo que as aulas expositivas têm como principal característica a exposição dos conteúdos, nas quais os estudantes participam das mesmas, contribuindo com seu conhecimento prévio.

As aulas práticas se referem à necessidade de envolvimento do estudante com a atividade proposta, para que o conhecimento possa ser construído a partir de atuações concretas (ANDRADE; MASSABNI, 20II), e através da experimentação, conciliando a teoria e a prática trabalhadas em sala de aula. As aulas laboratoriais podem ocorrer fora do ambiente escolar, porém, neste tipo de estudo, o aluno intervém no meio observado em busca de obter resultados para seu trabalho. As visitas técnicas se assemelham muito com aulas de campo, uma vez que permitem aos alunos aperfeiçoar o que aprendem em sala de aula e aprimorar a compreensão "in loco" dos termos técnicos e conceitos observados na prática (COSTA; ARAUJO, 2012).

Ainda que todas estas estratégias sejam excelentes alternativas metodológicas de ensino, as aulas de campo possibilitam a aprendizagem através de um ambiente não escolar, em que os alunos observam por si próprios o meio, relacionando com o que foi estudado em sala de aula. Fernandes (2007), define aula de campo ou atividade de campo como atividades escolares que são desenvolvidas fora da sala de aula, que envolve o deslocamento dos alunos para outros ambientes, sendo então, um espaço de realidade alheio à escola. Este tipo de aula faz com que o aluno exercite sua capacidade de apreender as informações do meio visitado, ver educação em espaços não formais.

As aulas de campo, além de trabalhar especificamente as disciplinas, também permitem uma interdisciplinaridade, já que conhecimentos de diversas áreas podem ser acionados para a compreensão e a discussão sobre o entorno ambiental, pois, quando realizadas em uma determinada região, os alunos além de aprenderem especificamente sobre o que foram observar, também aprenderão sobre a história, as características e até mesmo a geografia do local. Além disso, as aulas de campo também proporcionam o desenvolvimento cognitivo e psicológico através das experiências vivenciadas pelos alunos, já que estes se transformarão em conhecimento. Quando o professor fornece atividades diversificadas, está estimulando a curiosidade do aluno com um momento de diversão, e isso faz com que o docente busque a aprendizagem e desperte seu interesse pelos estudos (BRUST, 2009).

De acordo com Oliveira e Gastal (2009), a educação quando efetiva em um processo de aquisição e/ou construção de conhecimentos, contribui para o desenvolvimento cognitivo e comportamental nas mais variadas circunstâncias, desde que a atividade desenvolvida tenha uma qualidade capaz de torná-la marcante.

Assim, o objetivo deste estudo foi avaliar como as aulas de campo pode contribuir para o reforço de aulas teóricas no processo de ensino aprendizagem na disciplina de Apicultura no ensino superior, visto que em determinados conteúdos desta disciplina, é possível, e até mesmo necessário, se utilizar desta estratégia de ensino para relacionar o conhecimento científico com a realidade observada.

\section{METODOLOGIA}

O estudo foi desenvolvido na disciplina de Apicultura do curso de Agronomia da Universidade Federal da Fronteira Sul, campus Laranjeiras do Sul (PR), durante o período de agosto a dezembro de 2017. Por se tratar de uma disciplina optativa, a pesquisa foi realizada com uma turma mista, composta por 24 alunos em diferentes fases. 
O presente trabalho adotou a técnica de pesquisa exploratória para abordagem do tema, na tentativa de contribuir para o aprimoramento de estudos referentes à importância e impacto das aulas práticas de campo na disciplina de Apicultura. O procedimento se enquadrou dentro de uma pesquisa-ação, pois propõe a compreensão de um problema foco que é o ensino-aprendizagem e intervenção na situação estudada a fim de modificá-la, associando a ação com a resolução de um problema coletivo. Após esse procedimento, foi realizado um confronto do conteúdo programático aplicado na disciplina com possíveis situações de experimentação em aulas de campo que representem o fenômeno a ser abordado dentro da área de Apicultura. Esses dados foram importantes para definir como podem ser modelados as aulas de campo de acordo com a necessidade específica de cada disciplina e determinar quais os objetivos com seu uso para o ensino.

A identificação dos ganhos potenciais de conhecimento complementar no processo ensino aprendizagem foram efetuadas, experimentalmente, a partir de testes objetivos e subjetivos sobre o assunto abordado na disciplina e tratado com reforço de aulas de campo. Os testes foram elaborados com auxílio do professor da disciplina que atuou como supervisor do trabalho para sugerir quais pontos seriam importantes para se explorar na aprendizagem do conteúdo. Dentro da gama de possibilidades de experimentações em aulas de campo em Apicultura, foram escolhidas práticas que possibilitassem a avaliação rápida dos resultados, como o processo de captura de enxames.

Os conteúdos escolhidos para desenvolver os testes tratavam de assuntos rotineiros na prática da Apicultura, conhecidos como captura passiva e ativa de enxames. A captura passiva trata-se de um procedimento em que o apicultor não necessita manusear as colmeias, sendo a captura executada pelo uso de caixas iscas, contendo atrativos a base de soluções e feromônios para atrair e forçar a entrada das abelhas dentro da caixa. Já a captura ativa é o método em que o apicultor necessita manusear os favos naturais, organizando-os adequadamente dentro de uma caixa racional por introdução direta do cacho de abelhas ou por enquadramento dos favos de cria e de mel encontrados na colmeia natural (Figura r). Estes dois métodos de captura são utilizados para conduzir as abelhas até o apiário, e a transferência do enxame do local em que se encontram serve tanto para facilitar seu manejo, como também garantir a sobrevivência do enxame, já que em um apiário tem muito mais chance de sobreviver do que se permanecesse no local de origem.

Figura I. Alguns procedimentos adotados para a realização da prática de captura ativa de enxames.
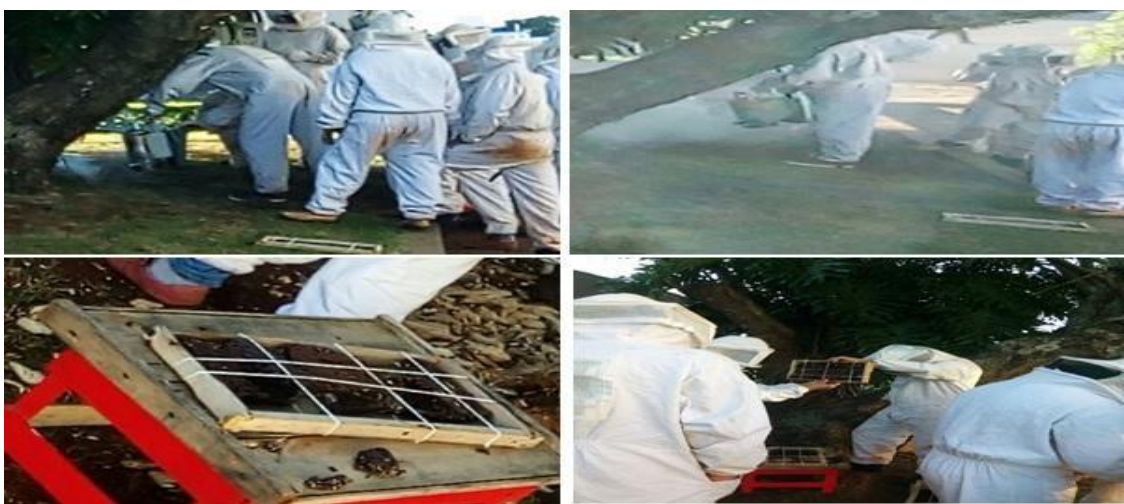

Fonte: Os autores (2017). 
Dois momentos específicos foram utilizados para a abordagem da avaliação, o préteste e o pós-teste. O pré-teste foi aplicado uma semana após a explanação do assunto de forma teórica em sala de aula de modo que o objeto do experimento (estudantes) não sofreram influência do fator, que nesse caso é a aula prática de campo. Já o pós-teste foi aplicado ao mesmo grupo de estudantes, uma semana após terem vivenciado a aula prática de campo, com o mesmo objetivo de verificar se esta experiência havia sido aprendida, consistindo no mesmo teste aplicado após a aula teórica, com as mesmas questões, tratandose de um teste repetitivo, com a finalidade de identificar a contribuição que as aulas de campo haviam proporcionado ao ensino do conteúdo.

O primeiro conteúdo trabalhado foi sobre captura passiva de enxames, sendo o pré e pós-testes sobre o assunto aplicados de forma subjetiva com três questões dissertativas (Quadro I). O segundo conteúdo tratado foi sobre a captura ativa de enxames, em que o pré e pós-testes aplicados se deram por meio de três questões de forma objetiva (Quadro 2).

Quadro I. Pré-teste/Pós-teste sobre captura passiva de enxames, aplicado aos estudantes na disciplina de Apicultura.

Questão I. O que é captura passiva?

Questão 2. Quais os materiais e equipamentos utilizados para se fazer uma captura passiva?

Questão 3. Quais as etapas ou procedimentos em sequência para desenvolver uma prática de captura passiva?

Fonte: Os autores (2017).

Quadro 2. Pré-teste/Pós-teste sobre captura ativa de enxames, aplicado aos estudantes na disciplina de Apicultura.

Questão I. No procedimento de captura de enxame é necessário a utilização da indumentária apícola ou macacão. A respeito do seu uso, podemos afirmar com V (verdadeiro) ou F (falso):

( ) A cor ideal para o macacão é a cor azul, porque nesse espectro de luz as abelhas se sentem mais confortáveis com a presença do operador.

( ) Não há nenhum problema na utilização de várias cores no macacão, apenas se utiliza o branco para questões de conforto térmico.

( ) O sentido do uso do macacão branco é a de possibilitar o conforto térmico e ao mesmo tempo diminuir o efeito de irritação das abelhas causados por contrastes de cores.

( ) Poderíamos usar macacões nas cores, azul, verde, ou amarelo, que não haveria nenhum problema, incluindo também o preto e o marrom.

( ) As luvas e as botas na extensão final dos braços e pernas devem ser colocados por cima do macacão.

( ) As luvas e as botas na extensão final dos braços e pernas devem ser colocados por baixo do macacão.

( ) Uma proteção integral e perfeita da cabeça é requisito absolutamente necessário para a manipulação tranqüila das colméias africanizadas. $O$ material mais recomendável para o visor das máscaras é o algodão. 
( ) Com relação as luvas de segurança recomenda-se o uso de luvas de couro fortes e resistentes, para a manipulação das colméias.

Questão 2. Com relação a utilização e manejo da cera alveolada, marque com $\mathrm{V}$ as informações julgadas verdadeiras, e com $\mathrm{F}$ as informações julgadas falsas:

( ) A cera alveolada é uma lâmina de cera prensada, que apresenta de ambos os lados o relevo dos alvéolos, que servirá de guia para as abelhas construírem os favos.

( ) A principal função da cera alveolada não inclui servir de guia e alinhamento para a construção dos favos.

( ) O uso de cera alveolada favorece o nascimento de zangões (machos), porque as células presentes nestas, se adéquam perfeitamente ao tamanho dos mesmos.

( ) A utilização de cera alveolada diminui o exaustivo trabalho das abelhas de produzirem cera e construir favos.

( ) Os favos ficam mais resistentes (fortes) e não quebram durante a centrifugação. ( ) Devido a utilização da cera alveolada, as abelhas desfrutam de menos tempo para aproveitar as floradas.

( ) As lâminas alveoladas são as melhores e mais usadas por serem inquebráveis ao dobrar.

( ) Quanto ao tamanho das células, as lâminas alveoladas são produzidas para abelhas operárias e em casos especiais para zangões.

Questão 3. Se tratando dos procedimentos necessários para a realização da captura ativa de enxames, marque $V$ nas informações tidas como verdadeiras, e $F$ para as informações tidas como falsas:

( ) Colocar no local de operação uma colméia de transferência com ninho, fundo, tampa, e com io quadros, sendo 4 quadros com cera alveolada e 6 sem cera e sem arame, uma tábua sulcada de amarrar favos, barbante, faca, tesoura, uma vasilha com água, martelo, formão de apicultor e um bom fumigador aceso.

( ) A prática da captura ativa deve ser realizada no período noturno, devido a se ter uma baixa na temperatura, o que faz com que as abelhas fiquem menos agitadas.

( ) Os quadros sem cera alveolada são empregados para aerar a colméia, permitindo uma melhor circulação das abelhas dentro da mesma.

( ) Deve-se borrifar a fumaça do fumigador o mais próximo possível das abelhas, para que esta seja mais eficiente.

( ) Recorta-se os favos e expulsa-se as abelhas dos favos varrendo-as para dentro da caixa de transferência utilizando uma vassoura de apicultor, faca ou espátula, com todo cuidado para não danificar a rainha.

( ) Deve-se depositar os favos em um recipiente aberto.

( ) A última etapa do processo de captura ativa é a transferência da rainha para a caixa apícola.

( ) Colocar a tampa sobre a caixa de transferência e escolher os favos de menor qualidade com cria, e amarrá-los nos quadros com cera alveolada.

Fonte: Os autores (2017).

\section{RESULTADOS E DISCUSSÃO}

O curso de graduação em Agronomia é essencialmente técnico, sendo que na maioria das disciplinas, as aulas práticas são, basicamente, a aplicação das técnicas que foram estudadas na teoria. Assim, como afirma Veiga (1989), teoria e prática constituem uma 
unidade indissolúvel, ou seja, uma depende da outra e ao mesmo tempo. Quando a prioridade é colocada na teoria cai-se na posição idealista e, se ocorre o inverso também gera distorções, uma vez que sem teoria não se sabe o que pratica. Portanto, a indissociabilidade dessas duas propostas consiste em um importante passo para que a formação profissional proporcione conhecimentos técnicos e teóricos, que junto com a análise crítica da realidade desenvolvem a problematização das relações sociais, políticas e econômicas em que o sujeito trabalhador está inserido (MORAIS; SOUZA; COSTA, 2017).

Os dados do pré-teste sobre captura passiva de enxames (Figura 2), mostraram que a maioria dos alunos, aproximadamente $42 \%$ dos estudantes, não atingiram notas acima de 6 . Isso demonstra que a explicação da matéria realizada apenas de forma teórica não foi suficiente para que os alunos conseguissem adquirir os conhecimentos técnicos necessários para resolver de maneira satisfatória os problemas propostos nos exercícios, o que evidencia a dificuldade de memorização quando a metodologia envolve apenas aulas com exposição teórica de um assunto.

$\mathrm{Na}$ aplicação do pós-teste, uma semana após o desenvolvimento da aula de campo, os estudantes apresentaram um ganho significante de rendimento no aprendizado, ficando todas a notas acima de 6 . Cerca de $54 \%$ dos alunos testados obtiveram notas entre 9, I e ro e $42 \%$ dos estudantes notas entre 7,6 a 9, demonstrando um aumento da eficiência da fixação do conteúdo com a adição da aula de campo (Figura 2). Ao analisar a prova dissertativa no experimento, após a aplicação da aula de campo, foi possível observar que os estudantes tiveram uma melhora na assimilação do conteúdo, havendo maior complexidade na elaboração de suas respostas, além de aplicar de forma mais adequada o uso de termos técnicos-científicos.

No pré-teste sobre captura ativa, foi observado que a maioria da turma alcançou notas acima da média 6 , porém, percebe-se que estas foram medianas e que $25 \%$ dos acadêmicos não alcançaram a média (Figura 3). Então, podemos enfatizar mais uma vez que apenas a aula teórica não foi suficiente para a compreensão total do conteúdo por parte dos estudantes, ficando evidente a necessidade de uma estratégia de ensino para servir de reforço da teoria

Já os dados obtidos na reaplicação do questionário sobre captura ativa (pós-teste), mostraram uma melhora nas notas dos estudantes (Figura 3), sendo que $64 \%$ dos acadêmicos obtiveram notas consideravelmente boas, apesar dos outros $36 \%$ terem alcançado notas medianas. No entanto, o importante foi que nenhum aluno ficou com nota abaixo da média, como havia ocorrido no pré-teste após a aula teórica, demonstrando o quanto a aula de campo auxiliou na compreensão do conteúdo.

Gráficos I. Relação de notas obtidas pelos alunos no pré-teste e pós-teste sobre captura passiva de exames. 


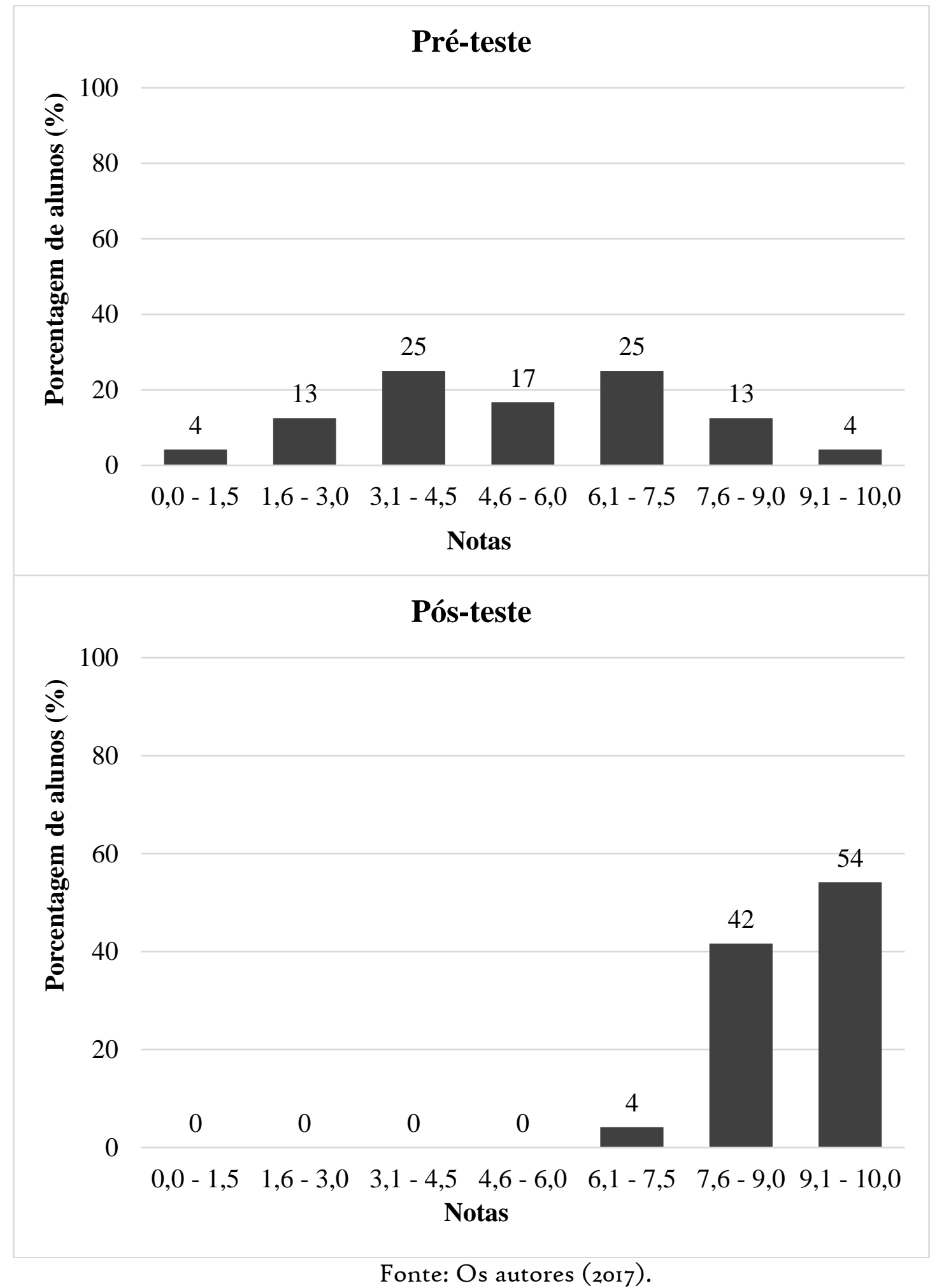

Gráficos 2. Relação de notas obtidas pelos alunos no pré-teste e pós-teste sobre captura ativa de enxames. 


\section{Pré-teste}
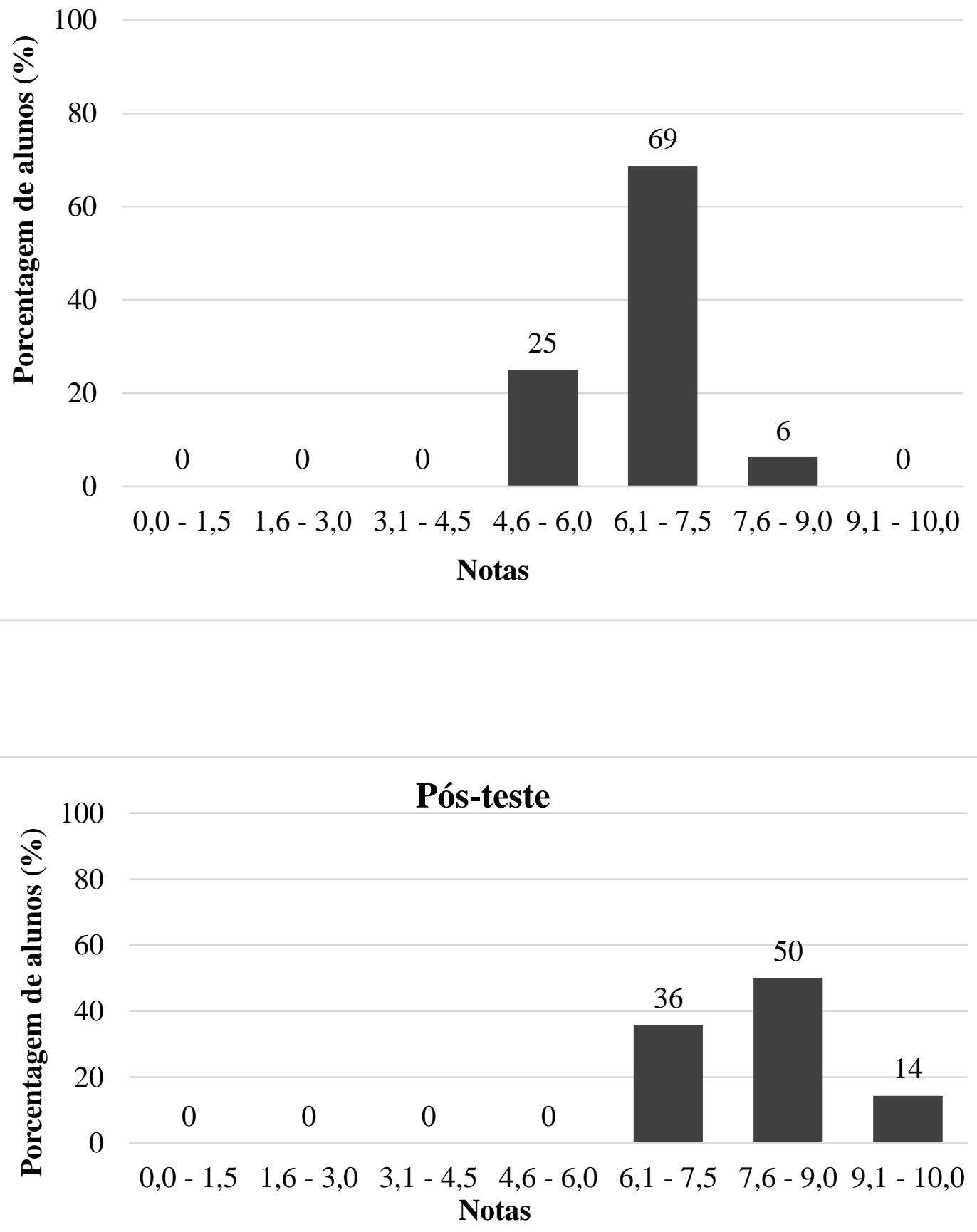

Fonte: Os autores (2017).

Resultados semelhantes ao presente estudo foram encontrados por Lima e Garcia (20II), os quais verificaram diferença significativa entre o desempenho das turmas de ensino médio que tiveram aulas práticas de biologia e as turmas que não tiveram. No entanto, segundo os autores, deve-se considerar que tais resultados são apenas indicativos de que as aulas práticas podem contribuir de alguma forma para melhorar o desempenho dos estudantes, porém, fatores como a metodologia de ensino, características das turmas e os recursos didáticos disponíveis nas aulas devem ser levados em consideração em futuras investigações. Estudos como de Leite et al. (2005) e Oliveira e Correia (2013), também 
constataram o quanto as aulas de campo podem contribuir e favorecer para o processo ensino-aprendizagem, sendo constatada a ampliação e o desenvolvimento do espírito crítico dos alunos acerca do tema estudado.

Kuenzer (2004), ao analisar as contribuições da formação inicial através da operação assistida, para a inserção de novos operadores na área de trabalho, verificou que a falta de articulação entre teoria e prática foi a que mais incomodou os novos operadores em seu processo de aprendizagem. Esta preocupação se deu a partir da comparação entre a primeira parte do curso de formação, eminentemente teórica, e a segunda parte, realizada fortemente vinculada à área de atuação industrial. A autora destaca ainda que, embora os entrevistados reconheçam que receberam uma boa base teórica, os mesmos não se sentiram motivados durante a formação básica, e que a formação específica foi mais envolvente por causas das aulas práticas e ainda contribuiu para a construção e efetivação dos conhecimentos.

Segundo Timoteo e Liberalino (2003), uma queixa frequente dos alunos universitários é que em grande parte dos cursos de graduação há a questão da supervalorização da teoria em detrimento da prática, o que revela a utilização de maneira inadequada do tempo no decorrer da disciplina e a ausência de reflexão sobre os conceitos teóricos no momento da prática. No estudo de Franco e Boog (2007), com professores do curso de graduação em Nutrição, evidenciou que para alguns professores a atividade prática, quando presente na disciplina, é entendida como a elaboração de instrumentos de apoio, sendo realizada de forma pontual, em sala de aula, e não relacionada a outras atividades, ficando a prática de campo restrita apenas aos estágios que ocorrem em momento posterior.

Amorim et al. (200I), apontam que o fato da maioria dos cursos de graduação realizarem as atividades de estágios no último ano, sendo este momento o primeiro e único que aproxima o aluno da teoria e da prática, gera dificuldades para a realização de redirecionamentos dos conteúdos trabalhados desde o primeiro ano do curso para a aplicação no meio de trabalho. Assim, independentemente da disciplina, a relação teórico-prática é importante desde o primeiro ano da graduação para que o acadêmico consiga estabelecê-la em todas as suas ações ao longo do curso (FRANCO; BOOG, 2007).

\section{CONSIDERAÇÕES FINAIS}

As evidências levantadas durante esta investigação possibilitaram enfatizar a importância da aula de campo na inclusão do acadêmico como um agente participativo no processo de aprendizagem, deixando de ser apenas um mero receptor de informações. A partir do momento em que o estudante faz parte do processo de ensino de maneira ativa o aprendizado se torna mais significativo, uma vez que se faz necessário a sua total atenção para o desenvolvimento da aula.

Os conceitos apresentados nas aulas teóricas são, em sua maioria, abstratos. Por isso a importância das aulas práticas para facilitar o aprendizado. Além de estratégicas, elas auxiliam o professor a retomar um assunto que já foi abordado anteriormente, sendo este o momento em que o aluno tem a oportunidade de realmente vivenciar na prática o que foi estudado dentro da sala de aula. Esse tipo de atividade possibilita que os estudantes sejam sempre incentivados a levantar questionamentos e hipóteses, levando ao desenvolvimento do senso crítico e o trabalho em equipe.

Os testes aqui aplicados serviram de base para concluirmos os impactos positivos que as aulas de campo podem causar na vida acadêmica dos estudantes, evidenciado pela melhora nas notas sobre o conteúdo que antes havia sido trabalhado somente de forma teórica. Outro 
fator importante, é que uma aula de campo com fins educacionais, necessita que, primeiramente, sejam trabalhados conceitos teóricos para se ter claro seu o objetivo e quais os procedimentos devam ser adotados.

\section{REFERÊNCIAS}

AMORIN, S. T. S. P. MOREIRA, H., CARRARO, T. E. A formação de pediatras e nutricionistas: a dimensão humana. Revista de Nutrição, v. 4, n. 2, p. II-I8, 200I. Disponível em: https://doi.org/10.1590/Si415-52732001000200004.

ANDRADE, M. L. F., MASSABNI, V. G. O desenvolvimento de atividades práticas na escola: um desafio para os professores de ciências. Ciência \& Educação, v. 17, n. 4, p. 835-854, 20II. Disponível em: http://www.scielo.br/scielo.php?script=sci_arttext\&pid=Si5ı673132011000400005 .

BRUST, J. R. A influência da afetividade no processo de aprendizagem de crianças nos anos iniciais do ensino fundamental. 2009. 40 f. Trabalho de Conclusão de Curso (Graduação em Pedagogia). Universidade Estadual de Londrina, Londrina, 2009. Disponível em http://www.uel.br/ceca/pedagogia/pages/arquivos/JOSIANE\%2oREGINA\%2oBRUST. pdf.

COSTA, M. N. M. G., ARAÚJO, R. P. A importância da visita técnica como recurso didático metodológico. Um relato na prática do IFSertão Pernambucano. In. CONGRESSO NORTE NORDESTE DE PESQUISA E INOVAÇÃO, 7, 2012, Palmas. Anais... Palmas: ISBN, 2012. $\quad$ Disponível em http://propi.ifto.edu.br/ocs/index.php/connepi/vii/paper/view/1335/2166.

FERNANDES, J. A. B. Você vê essa adaptação? A aula de campo em ciências entre o retórico e o empírico. 2007. 326 f. Tese (Doutorado em Educação) - Universidade de São Paulo, Faculdade de Educação, São Paulo, 2007. Disponível em http://www.teses.usp.br/teses/disponiveis/48/48134/tde-I4062007-16584I/pt-br.php.

FRANCO, A. C., BOOG, M. C. F. Relação teoria-prática no ensino de educação nutricional. Revista de Nutrição, v. 20, n. 6, p. 643-655, 2007. Disponível em: https://doi.org/I0.1590/SI415-52732007000600007.

KUENZER, A. Z. Competência como práxis: os dilemas da relação entre teoria e prática na educação dos trabalhadores. Boletim Técnico do Senac, v. 30, n. 3, p. 81-93, 2004. Disponível em: https://www.bts.senac.br/bts/article/view/5or.

LEITE, A. C. S., SILVA, P. A. B., VAZ, A. C. R. A importância das aulas práticas para alunos jovens e adultos: uma abordagem investigativa sobre a percepção dos alunos do PROEF II. Revista Ensaio Pesquisa em Educação em Ciência, v. 7, n. 3, p. I66-I8I, 2005. Disponível em: https://doi.org/10.1590/1983-21172005070302.

LIMA, D. B., GARCIA, R. N. Uma investigação sobre a importância das aulas práticas de Biologia no Ensino Médio. Cadernos do Aplicação, v. 24, n. I, p. 201-224, 20II. Disponível em: https://www2.ifrn.edu.br/ojs/index.php/RBEPT/article/view/5720/pdf.

MORAIS, J. M., SOUZA, A. P., COSTA, T. A relação teoria e prática: investigando as compreensões de professores que atuam na educação profissional. Revista Brasileira da 
Educação Profissional Tecnológica, v. I, n. I2, p. III-I24, 2017. Disponível em: https://doi.org/10.15628/rbept.2017.5720.

OLIVEIRA, A. P. L., CORREIA, M. D. Aula de campo como mecanismo facilitador do ensino aprendizagem sobre os ecossistemas recifais em Alagoas. ALEXANDRIA: Revista de Educação em Ciência e Tecnologia, v. 6, n. 2, p. 163-190, 2013. Disponível em: https://periodicos.ufsc.br/index.php/alexandria/article/view/37996/28997.

OLIVEIRA, R. I. R.; GASTAL, M. L. A. Educação formal fora da sala de aula - olhares sobre o ensino de Ciências utilizando espaços não-formais. In: ENCONTRO NACIONAL DE PESQUISA EM EDUCAÇÃO EM CIÊNCIAS, 7, 2009, Florianópolis. Anais... Florianópolis: ISSN, 2009. Disponível em: http://posgrad.fae.ufmg.br/posgrad/viienpec/pdfs/r674.pdf.

PIAZZI, P. Aprendendo inteligência. Editora Aleph, zº ed. São Paulo-SP, 2008, P. I40.

TIMOTEO, R. P. S., LIBERALINO, F. N. Reflexões acerca do fazer pedagógico a partir de referências e diretrizes educacionais para a formação em enfermagem. Revista Brasileira de Enfermagem, v. 56, n. 4, p. 358-360, 2003. Disponível em: https://doi.org/10.1590/Soo3471672003000400008 .

VEIGA, I. P. A. A Prática pedagógica do professor de didática. Editora Papirus, Io ed. Campinas,-SP, 1989. P. 183. 1989.

VIVEIRO, A. A., DINIZ, R. S. As atividades de campo no ensino de ciências: reflexões a partir das perspectivas de um grupo de professores. In: NARDI, R. (Org.). Ensino de ciências e matemática, I: temas sobre a formação de professores. São Paulo: UNESP, 2009. cap. 2, p. 27-42. Disponível em http://books.scielo.org/id/g5q2h/pdf/nardi-978857983004403.pdf. 